\title{
Patients' Beliefs About Racism, Preferences for Physician Race, and Satisfaction With Care
}

\author{
Frederick $M$. Chen, $M D, M P H^{1}$ \\ George E. Fryer, Jr, PbD \\ Robert L. Pbillips, Jr, MD, MSPH ${ }^{2}$ \\ Elisabeth Wilson, $M D, M P H^{3}$ \\ Donald E. Pathman, MD, MPH \\ ${ }^{1}$ Center for Primary Care, Prevention, and \\ Clinical Partnerships, Agency for Healthcare \\ Research and Quality, Rockville, Md \\ ${ }^{2}$ The Robert Graham Center: Policy Studies \\ in Family Practice and Primary Care, \\ Washington, DC \\ ${ }^{3}$ Department of Family and Community \\ Medicine, University of California, \\ San Francisco, Calif \\ ${ }^{4}$ Department of Family Medicine and \\ Cecil G. Sheps Center for Health Services \\ Research, University of North Carolina at \\ Chapel Hill, NC
}

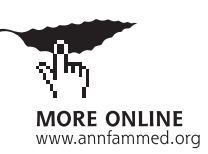

Conflicts of interest: none reported

\section{CORRESPONDING AUTHOR}

Frederick Chen, MD, MPH Department of Family Medicine Box 354982

University of Washington

Seattle, WA 98195

fchen@u.washington.edu

\begin{abstract}
PURPOSE Few studies have attempted to link patients' beliefs about racism in the health care system with how they use and experience health care.

METHODS Using telephone survey data from a national sample of 1,479 whites, 1,189 African Americans, and 983 Latinos, we explored patients' beliefs about racism, their preferences for the race and ethnicity of their physician, and their satisfaction with that physician. A scale was developed to reflect patients' beliefs about racism. Race-stratified analyses assessed associations between patients' beliefs, racial preferences for physicians, choice of physician, and satisfaction with care.

RESULTS Among African Americans, stronger beliefs about racial discrimination in health care were associated with preferring an African American physician $(P<.001)$. Whereas only $22 \%$ of African Americans preferred an African American physician, those who preferred a African American physician and had an African American physician were more likely to rate their physician as excellent than did African Americans who preferred a African American physician but had a non-African American physician ( $57 \%$ vs $20 \%, P<.001$ ). Latinos with stronger beliefs about discrimination in health care were more likely to prefer a Latino physician $(P<.001)$. One third of Latinos preferred a Latino physician. Though not statistically significant, those who preferred and had a Latino physician rated their physician higher than Latinos who preferred a Latino physician but had a non-Latino physician (40\% vs $29 \%$ ).
\end{abstract}

CONCLUSIONS Many African Americans and Latinos perceive racism in the health care system, and those who do are more likely to prefer a physician of their own race or ethnicity. African Americans who have preferences are more often satisfied with their care when their own physicians match their preferences.

Ann Fam Med 2005;3:138-143. DOI: 10.1370/afm.282.

\section{INTRODUCTION}

$\mathrm{R}$ acial and ethnic disparities are a major problem in the US health care system. ${ }^{1}$ Racial differences have been documented in access to care, receipt of needed medical care, preventive services, and lifesaving technologies. ${ }^{2-7}$ There is, however, considerable uncertainty around the factors that contribute to racial disparities in health care. ${ }^{8}$ Although disparities can be explained in part by differences in access to care, socioeconomic conditions, or even bias from health care physicians, the role of patients' beliefs and preferences remains unclear. ${ }^{9,10}$

What is the connection between patients' racial beliefs and biases and their preferences for the race of their health caregivers? Shared language, social experiences, and cultural beliefs may drive some preferences., ${ }^{41,12}$ At the same time, the dubious experience of American medical research in minorities has fostered racial suspicions among some groups. ${ }^{13}$ Several studies have examined patients' racial preferences toward their health 
caregiver. ${ }^{14-16}$ Although some have documented patients' preferences for clinicians of the same race and a subsequent association with patient satisfaction, the factors that contribute to patients' preferences remain unclear. ${ }^{15-22}$

Using a national survey of African Americans, Latinos, and whites, we examined the link between patients' beliefs about racism, their racial and ethnic preferences for their own physicians, and their satisfaction with health care. We sought to answer the question: Are patients' beliefs about racism in the health care system associated with their preference for the race or ethnicity of their physician, and subsequently their satisfaction with that physician?

\section{METHODS}

\section{Conceptual Framework}

We sought to test a model that links individual patients' beliefs about racism in the US health care system, specific racial or ethnic preferences for their personal physician, the race of their regular physician, and their satisfaction with that physician. For this study, racism was defined as "people being treated worse than others because of their race or ethnicity. ${ }^{123}$ We hypothesized that minority patients who believe there is discrimination in the US health care system would prefer minority physicians. We also hypothesized that minority patients with these preferences who had a race- or ethnicity-concordant physician would report greater satisfaction with their physicians than patients in a race-discordant relationship.

\section{Survey Data}

We analyzed data gathered by the 1999 Kaiser Family Foundation Survey of Race, Ethnicity, and Medical Care: Public Perceptions and Experiences. The survey was based on a national sample of 3,884 telephone interviews with adults 18 years old and older, including 1,479 whites, 1,189 African Americans, and 983 Latinos. ${ }^{23}$ African Americans and Latinos were purposely oversampled during the data collection, and interviews were conducted in either English or Spanish. ${ }^{23}$ Among eligible sampled telephone numbers, the response rate was $49 \%$. The primary focus of the survey was to assess public awareness and perceptions of racism in health care. The original survey analysis did not examine how respondents' perceptions of racism affected their preferences or satisfaction.

Respondents' preference for the race of their physician was assessed with a single survey item which asked, "If you had to choose, would you prefer to be treated by a doctor or nurse of your own race or ethnic group, or not?" Respondents were given the option of preferring their own race, not preferring their own race, or "doesn't matter." Respondents who reported having a regular physician or health care clinician were asked to identify the race of that clinician. These respondents were also asked to rate their satisfaction with that physician, using a letter-grade rating ranging from $\mathrm{A}$ for excellent to $\mathrm{F}$ for failing. Because patient satisfaction ratings tend toward the positive, we chose to characterize patient satisfaction as patients rating $\mathrm{A}$ or excellent vs all other ratings.

Although there were specific survey items for racial preference and physician satisfaction, there was no single item that characterized patients' beliefs about racism in health care. Consequently, the 5 authors independently identified survey items that they believed reflected patients' beliefs about racism. Through an iterative consensus process, 9 survey items were identified and combined into a summated discriminatory belief scale. The 9 items are displayed in the Supplemental Table (which can be found online only at http:// www.annfammed.org/cgi/content/full/3/2/138/ DC1). These items focused on various aspects of racism in health care, including unfair treatment, access to services, quality of care, and cost. We sought a measure of patients' belief about racism in the health care system as a whole; therefore, we did not explore specific patient-physician interactions. All of the items were scaled with either 3 or 4 Likert categories. The raw scale score ranged from 9 to 30 . The scores were then transformed by subtraction from the maximum score, so that higher scale values signify perceptions of greater racial discrimination in health care. The discriminatory belief scale showed robust reliability for both African Americans and Latinos (Cronbach $\alpha=.806$ and .776, respectively). The scale was not created for white respondents because whites were asked only about racism in health care toward African Americans and Latinos, not whites; therefore, whites' responses to these items reflected only beliefs about discrimination toward other races and did not fit the conceptual framework for the discriminatory belief scale.

\section{Analysis}

We performed race-stratified analyses to assess associations between the discriminatory belief scale and racial preferences; between racial preferences and reported race and ethnicity of patients' personal physicians; and between patient-physician racial concordance and patients' satisfaction. Pearson $\chi^{2}$ tests were used to examine bivariate comparisons of racial preferences, concordance, and patients' satisfaction ratings. The discriminatory belief scale scores were analyzed using one-way analysis of variance. Some items in the survey questionnaire were asked only to a random one half of 


\begin{tabular}{|c|c|c|c|}
\hline Characteristic & $\begin{array}{c}\text { Percent } \\
\text { African } \\
\text { American } \\
\mathrm{n}=1189\end{array}$ & $\begin{array}{c}\text { Percent } \\
\text { Latino } \\
\mathrm{n}=983\end{array}$ & $\begin{array}{c}\text { Percent } \\
\text { White } \\
\mathrm{n}=1479\end{array}$ \\
\hline Male & 41 & 44 & 45 \\
\hline \multicolumn{4}{|l|}{ Age, years } \\
\hline $18-44$ & 63 & 78 & 52 \\
\hline $45-65$ & 27 & 18 & 31 \\
\hline$>65$ & 10 & 4 & 17 \\
\hline Household Income $>\$ 25,000$ & 57 & 43 & 71 \\
\hline Education $\geq$ high school diploma & 81 & 64 & 84 \\
\hline Self-rated health excellent & 27 & 24 & 31 \\
\hline Have a regular doctor & 85 & 68 & 83 \\
\hline Discriminatory belief scale (range $0-21$ ) & 12.4 & 11.0 & $\mathrm{n} / \mathrm{a}$ \\
\hline Prefer same race physician & 22 & 34 & 13 \\
\hline Prefer different race physician & 13 & 19 & 11 \\
\hline No preference in race of physician & 65 & 47 & 76 \\
\hline Racial concordance with physician & 27 & 35 & 76 \\
\hline Physician rated as excellent & 47 & 45 & 50 \\
\hline
\end{tabular}

Figure 1. Associations between Discriminatory Belief Scales scores and the preferred racelethicity of one's doctor.

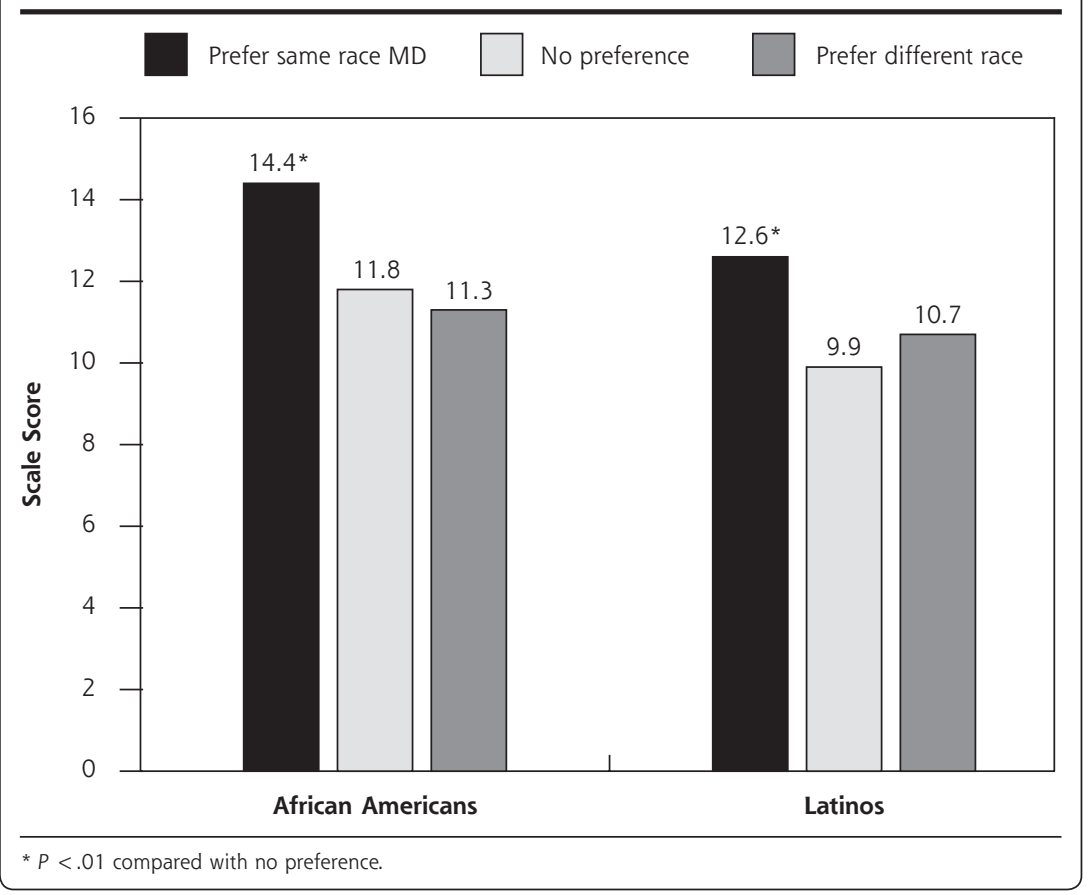

only secondary data and was exempted from review by the University of North Carolina at Chapel Hill Committee on the Protection of the Rights of Human Subjects.

\section{RESULTS}

Characteristics of survey respondents are displayed in Table 1. Among African Americans in the survey, only $22 \%$ preferred an African American physician, and $65 \%$ had no racial preference. Thirteen percent of African Americans preferred a non-African American physician. Among Latinos, 34\% preferred a Latino physician, and $47 \%$ had no preference. Nineteen percent of Latinos specifically preferred a non-Latino physician. Only $13 \%$ of whites preferred a white physician and three-quarters of whites had no preference for the race of their physician.

By mean discriminatory belief scale scores, African Americans had stronger beliefs about racial discrimination in health care than Latinos (12.4 vs 11.0, $P<.001$ ). More importantly, the scores of the discriminatory belief scale were strongly associated with patients' racial preferences for their physician. African Americans who preferred an African American physician had stronger beliefs about racial discrimination in health care than African Americans who had no preference (mean scores, 14.4 vs $11.8, P<.001)$. African Americans who preferred non-African American physicians had similar discriminatory belief scores as those who did not have a

the sample population. As a result, regression analyses using individual respondents' characteristics were not performed. In addition, the random half-sampling resulted in small cell sizes in some comparisons and precluded the use of weights and design effects in the analysis. All analyses were performed with SPSS version 11.5 (SPSS, Inc, Chicago, I1l). This study used racial preference. There was a similar pattern of associations among Latinos (Figure 1).

Patients' racial preferences were associated with the race of the patients' regular physicians. Among African Americans, 39\% who preferred an African American physician had a African American physician, while only $27 \%$ of those without a preference had an Afri- 


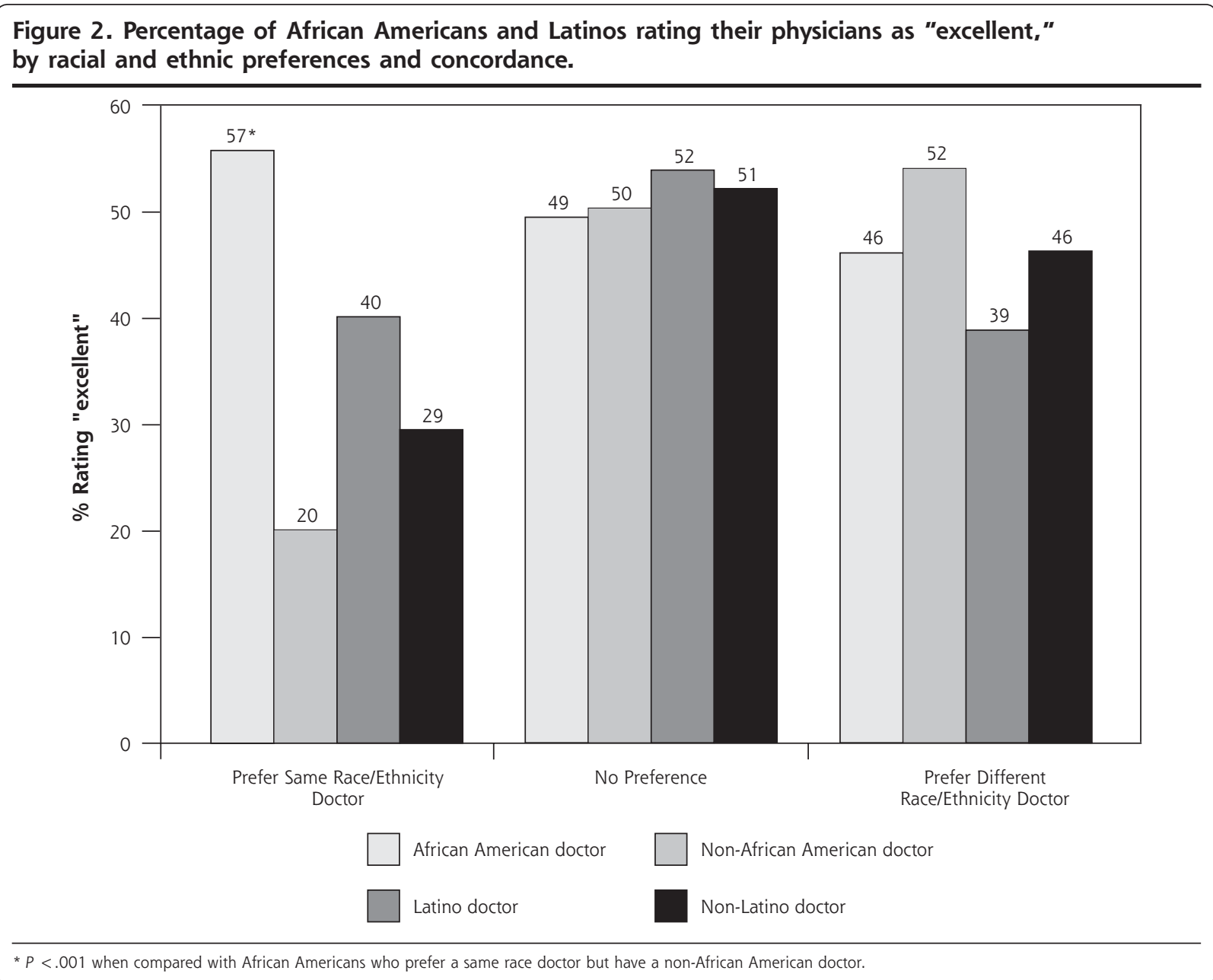

can American physician $(P=.03)$ and $21 \%$ of African Americans who preferred a non-African American physician had an African American physician $(P=N S$, compared with no preference). Similarly, Latinos who preferred a Latino physician were more likely to have a Latino physician (47\% vs $31 \%, P=.005)$. Thirty-seven percent of Latinos who preferred a non-Latino physician had a Latino physician ( $P=\mathrm{NS}$, compared with no preference). For whites there was no significant relationship between preference and race.

Finally, there was a strong relationship between patient preference, racial concordance, and patient satisfaction. African Americans who preferred an African American physician and had an African American physician were nearly 3 times more likely to rate their physician as excellent than were African Americans who preferred an African American physician and had a non-African American physician (57\% vs 20\%, P $<.001)$. African Americans with no racial preference rated their satisfaction with their physicians similarly, regardless of whether their physicians were African American (49\% vs 50\%, P = NS). African Americans who preferred non-African American physicians rated their satisfaction with African American physicians similarly to African Americans who preferred non-African American physicians and did not have African American physicians ( $46 \%$ vs $52 \%, P=\mathrm{NS}$ ) (Figure 2 ).

Latinos who preferred a Latino physician and had a Latino physician were no more likely to rate their physician as excellent than Latinos who preferred a Latino physician but had a non-Latino physician (40\% vs $29 \%, P=N S$ ). Latinos who did not have a racial preference and had a Latino physician rated their physicians similarly to Latinos who did not have a Latino physician ( $52 \%$ vs $51 \%, P=\mathrm{NS}$ ). Latinos who preferred non-Latino physicians rated their Latino physicians similarly to patients who had non-Latino physicians (39\% vs $46 \%, P=\mathrm{NS}$ ) (Figure 2).

Among whites, the number of white patients who preferred a white physician but did not have one was small, making up less than $2 \%$ of the entire sample. Regardless, a similar relationship was found, with $54 \%$ of whites who preferred and had a white physician rating their physicians as excellent compared with only 
$29 \%$ of whites who preferred a white physician but had a nonwhite physician $(P=.03)$. Whites who did not have a racial preference rated their physicians similarly, regardless of race.

\section{DISCUSSION}

This study reveals an association between patients' beliefs about discrimination in health care and specific preferences for the race or ethnicity of their physician. Patients' preferences for a same-race or same-ethnicity physician were also associated with a greater likelihood of race-concordant patient-physician relationships. In turn, patients who had racial preferences for their physicians were more likely to rate their regular physician highly if they were in a race-concordant relationship.

Importantly, nearly one quarter of African Americans and one third of Latinos preferred that their personal physician was of their same race or ethnicity. For these patients, racial beliefs and preferences may affect the quality of their interaction with their physician, and may be a factor in racial disparities in health care. It is possible that patients with strong racial preferences who are in race-discordant relationships may trust their physicians less, be less likely to follow their physicians' recommendations, may not understand their physician, and may be less likely to develop an otherwise therapeutic relationship. On the other hand, it bears emphasizing that not all minority patients want or need minority physicians. One challenge for work in racial and ethnic health care disparities is determining which patients have strong beliefs about discrimination in health care.

These results shed light on an association between patient preferences, racial and ethnic concordance, and patient satisfaction, but the true mechanisms at work in these relationships have only begun to be elucidated. A recent study by Cooper et al showed that racially concordant visits were longer and had more positive communication characteristics. ${ }^{22}$ While these patientoriented factors may be a component to understanding racial disparities in health care, the solutions deriving from this work are not readily apparent. Although these data could not show whether patients were able to act upon their beliefs or preferences, providing patients with better information about physicians and improving mechanisms for patients to choose their own physicians may be potential policy solutions.

As with any study, there are limitations to this analysis. Foremost, all of the results show associations, and no temporal relationship can be discerned from these data. For example, it is plausible that African American patients may have developed strong beliefs about racism based on experiences with a white physician. We are reassured, however, by the uniformity of these results among all 3 racial groups and the strength of the associations that confirmed our a priori hypothetical model. In addition, the concordance and preference results are consistent with previously published work. ${ }^{11,14,18,19,22}$ It is also important to note that, although the results have been presented in terms of personal physicians, the survey questionnaire asked respondents about their "physician or other health care provider." This distinction does not affect the findings but rather broadens the scope of patients' preferences and satisfaction. The race and ethnicity of physicians and clinicians was reported by patients and might not always be accurate. On the other hand, it can be argued that in studies of patients' racial and ethnic preferences, it is precisely the patient's perception that matters most. It is also possible that minority patients might feel pressured to report greater satisfaction with their minority physicians, although satisfaction ratings were similarly high for all racial groups. Finally, although the survey response rate (49\%) was only slightly lower than previously reported rates, nonresponse bias is a potential limitation of our study. ${ }^{24}$ Data on nonresponders were not available for analysis.

Although most evidence suggests that racial and ethnic health disparities are primarily related to social and economic causes, the contributions of bias, discrimination, and stereotyping can not be ignored. Our findings help to illuminate the role of patients' beliefs and preferences upon the nature of their relationship with their physician and their satisfaction with the care they receive. The sources of patients' beliefs about racism and discrimination are deep-seated and complex and will require similarly thoughtful and multifaceted solutions. The solutions for racial and ethnic disparities in health will need to go beyond increasing the number of minority physicians and attempting to teach cultural competence; rather, addressing discrimination in the health care system, increasing access to minority physicians, and improving the ways for patients to choose physicians may be more potent options for reducing racial disparities.

To read or post commentaries in response to this article, see it online at http://www.annfammed.org/cgi/content/full/3/2/138.

Key words: Delivery of health care; health services research; ethnic groups; minority groups; prejudice; patient satisfaction

Submitted March 29, 2004; submitted, revised, July 26, 2004; accepted September 1, 2004.

A version of this report was presented at the 31st Annual North American Primary Care Research Group Meeting, Banff, Canada, October 25-28, 2003.

Disclaimer: The views expressed are those of the authors and no official endorsement by the Agency for Healthcare Research and Quality is intended or should be inferred. 


\section{References}

1. Institute of Medicine. Unequal Treatment: Confronting Racial and Ethnic Disparities in Health Care. Washington, DC: National Academies Press; 2002.

2. Collins TC, Clark JA, Petersen LA, Kressin NR. Racial differences in how patients perceive physician communication regarding cardiac testing. Med Care. 2002;40(1 Suppl):127-134.

3. Ayanian JZ, Cleary PD, Weissman JS, Epstein AM. The effect of patients' preferences on racial differences in access to renal transplantation. N Engl J Med. 1999;341:1661-1669.

4. Doescher MP, Saver BG, Franks P, Fiscella K. Racial and ethnic disparities in perceptions of physician style and trust. Arch Fam Med. 2000;9:1156-1163

5. Corbie-Smith G, Flagg EW, Doyle JP, O'Brien MA. Influence of usual source of care on differences by race/ethnicity in receipt of preventive services. J Gen Intern Med. 2002;17:458-464.

6. Wenneker MB, Epstein AM. Racial inequalities in the use of procedures for patients with ischemic heart disease in Massachusetts. JAMA. 1989;261:253-257.

7. Sheifer SE, Escarce JJ, Schulman KA. Race and sex differences in the management of coronary artery disease. Am Heart J. 2000;139:848857.

8. Oddone EZ, Horner RD, Johnston DC, et al. Carotid endarterectomy and race: do clinical indications and patient preferences account for differences? Stroke. 2002;33:2936-2943.

9. Kressin NR, Clark JA, Whittle J, et al. Racial differences in healthrelated beliefs, attitudes, and experiences of VA cardiac patients: scale development and application. Med Care. 2002;40(1 Suppl):I72-185.

10. van Ryn M. Research on the provider contribution to race/ethnicity disparities in medical care. Med Care. 2002;40(1 Supp):140-151.

11. Saha S, Komaromy M, Koepsell TD, Bindman AB. Patient-physician racial concordance and the perceived quality and use of health care. Arch Intern Med. 1999;159:997-1004.

12. Schecter AD, Goldschmidt-Clermont PJ, McKee G, et al. Influence of gender, race, and education on patient preferences and receipt of cardiac catheterizations among coronary care unit patients. Am J Cardiol. 1996;78:996-1001.
13. Corbie-Smith G, Thomas SB, St George DM. Distrust, race, and research. Arch Intern Med. 2002;162:2458-2463.

14. Moy E, Bartman BA. Physician race and care of minority and medically indigent patients. JAMA. 1995;273:1515-1520.

15. Saha S, Taggart SH, Komaromy M, Bindman AB. Do patients choose physicians of their own race? Health Aff (Millwood). 2000;19:76-83.

16. Gray B, Stoddard JJ. Patient-physician pairing: does racial and ethnic congruity influence selection of a regular physician? J Community Health. 1997;22:247-259.

17. Howard DL, Konrad TR, Stevens C, Porter CQ. Physician-patient racial matching, effectiveness of care, use of services, and patient satisfaction. Res Aging. 2001;23:83-108.

18. Saha S, Arbelaez JJ, Cooper LA. Patient-physician relationships and racial disparities in the quality of health care. Am J Public Health. 2003;93:1713-1719.

19. Cooper-Patrick L, Gallo JJ, Gonzales JJ, et al. Race, gender, and partnership in the patient-physician relationship. JAMA. 1999;282:583589.

20. Murray-Garcia JL, Selby JV, Schmittdiel J, Grumbach K, Quesenberry CP, Jr. Racial and ethnic differences in a patient survey: patients' values, ratings, and reports regarding physician primary care performance in a large health maintenance organization. Med Care. 2000;38:300-310.

21. Whittle J, Conigliaro J, Good CB, Joswiak M. Do patient preferences contribute to racial differences in cardiovascular procedure use? J Gen Intern Med 1997;12:267-273.

22. Cooper LA, Roter DL, Johnson RL, Ford DE, Steinwachs DM, Powe NR. Patient-centered communication, ratings of care, and concordance of patient and physician race. Ann Intern Med. 2003;139:917915.

23. Lillie-Blanton M, Brodie M, Rowland D, Altman D, McIntosh M. Race, ethnicity, and the health care system: public perceptions and experiences. Med Care Res Rev. 2000;57(Suppl 1):218-235.

24. Asch DA, Jedrziewski MK, Christakis NA. Response rates to mail surveys published in medical journals. J Clin Epidemiol. 1997;50:1129. 1136. 